\title{
NATURAL CROSSING BETWEEN HOMOSTYLE PLANTS OF PRIMULA VULGARIS
}

\author{
W. F. BODMER \\ Department of Genetics, University of Cambridge
}

Received 6.xii.57

\section{INTRODUCTION}

IN the distylic Primula vulgaris the pin plants with long styles and low anthers, are recessive (ss) to the thrum plants $(S s)$, which have short styles and high anthers. The naturally occurring homostyles have long styles and high anthers and are the result of a change in the gene complex determining the heterostyly (Ernst, 1928). The changed gene complex may be considered as a gene $S^{h}$, recessive to the thrum gene $S$, and dominant to the pin gene $s$. Pollen from anthers at a given level is not inhibited in its growth on stigmas at the same level whereas it is on those at different levels, so that the homostyles are fully self-fertile. The self-compatibility of the homostyles together with the close proximity of the stigma and anthers, has led to the belief that the majority of homostyle plants are selfpollinated. Thus Crosby (1949) did not consider the possibility of crossing, in the explanation he put forward to account for the varying proportions of homostyles found in extensive counts of natural populations.

It is the purpose of this paper to present evidence in favour of the occurrence of natural crossing between the homostyle plants, and discuss its bearing on population studies.

\section{THE EXTENT OF CROSS-FERTILISATION}

In 1946 a number of homostyle plants were brought by Professor Sir Ronald Fisher from Sparkford, Somerset, to the Genetics Department at Cambridge, where for several years homostyles, from segregating progenies, were allowed to pollinate in open-pollination plots and their progenies grown. Assuming that the homostyles selfed, flowers taken from segregating progenies would have the genotypes $S^{h_{S}}$ or $S^{h} S^{h}$, according to whether pins appeared in their progenies or not. In one or two of the early years thrum plants were put in the plots. The progenies of some of the homostyles from these plots were then found to contain thrums, which could only have arisen through crossing of the thrums onto the homostyles. Now, since thrum plants were not subsequently used in any of the plots, the possible legitimate crosses involving female homostyle parents are $S^{h} S^{h} \times S^{h} S^{h}, S^{h} S^{h} \times S^{h} s$, $S^{h} S \times S^{h} S^{h}$ and $S^{h} s \times S^{h} s$, of which only the latter could give rise to pins. Hence, if $\alpha$ is the proportion of plants which are the result of 
self-fertilisation, $v: I_{-}-v$ is the proportion of the genotypes $S^{h} S: S^{h} S^{h}$ ariongst the homostyle parents and the illegitimate cross $S^{h}{ }^{k} \times s s$ is neglected, the expected proportion of pins amongst the progeny of segregating homostyles is $p=\mathrm{I} / 4(\alpha+v(\mathrm{I}-\alpha))$. This decreases from I $/ 4$ to $v / 4$ as $\alpha$ decreases from I to o. Thus the significant deficiency of pin plants amongst the progenies of supposedly selfed homostyles provides further evidence for crossing.

If the observed frequency is $a / n$ or $\gamma$, say, the maximum likelihood estimate for $\alpha$ is $(4 \gamma-v) /(1-v)$ with an estimated variance of I $6 a(n-a) / n^{3}(\mathrm{I}-v)^{2}$.

The proportion of pins recorded in segregating progenies for the years 1946 to 1955 is given in table $\mathrm{I}$.

TABLE I

\begin{tabular}{|c|c|c|}
\hline Year & $\begin{array}{c}\text { Proportion of pins } \\
\text { in segregating progenies }\end{array}$ & $\begin{array}{l}\chi^{2}{ }_{1} \text { for deviation } \\
\text { from } I: 3\end{array}$ \\
\hline $\begin{array}{l}1946 \\
1947 \\
1948 \\
1950 \\
1951 \\
1952 \\
1953 \\
1954 \\
1955\end{array}$ & $\begin{array}{l}4 / 34 \\
\text { I } 7 / 104 \\
47 / 257 \\
37 / 212 \\
36 / 17 \text { I } \\
\text { I0/54 } \\
29 / 164 \\
26 / 134 \\
\text { I } 19 / 45^{2}\end{array}$ & $\begin{array}{l}3 \cdot 1757 \\
4 \cdot 1538 \\
6 \cdot 175^{2} \\
6 \cdot 4402 \\
1 \cdot 4210 \\
1 \cdot 2097 \\
4 \cdot 6828 \\
2 \cdot 2383 \\
0 \cdot 424^{8}\end{array}$ \\
\hline & $325 / 1582$ & 16.7560 \\
\hline
\end{tabular}

The $\chi^{2}$ on the total, for deviation from the expected $\mathrm{I}: 3$ ratio when $s=\mathrm{I}$, is highly significant with $\mathrm{P}<\mathrm{O} \cdot \mathrm{I}$ per cent. A heterogeneity $\chi^{2}$ for all the years gives $15 \cdot 1232$ for eight degrees of freedom, the 5 per cent. point being 15.507 , whereas for the years 1946-54 only, the corresponding value is 2.3590 for seven degrees of freedom. A further test shows that the difference between 1955 and the other years is significant with $\mathrm{P}<\mathrm{I}$ per cent., indicating that in 1955 there was apparently no or very little crossing whereas in the previous years the proportion of crossing had been more or less uniform.

If we assume no viability disturbances, $v$ varies slightly about $2 / 3$, the variation depending on the frequency of crossing. The proportion of segregating progenies recorded, however, shows no significant deviation from $2 / 3$, and, taking $v$ at this value, the estimated proportion of crossing, derived from the years $1946-54$ only, is $82 \cdot 24$ per cent. with a standard error of 17.67 per cent. The effect of assuming a lower viability for the homozygous homostyles $\left(S^{h} S^{h}\right)$ relative to the heterozygous homostyles $\left(S^{h} s\right)$, as Crosby proposes, is to increase the proportion of pins to homostyles. Thus, the lower the viability assumed for the $S^{h} S^{h}$ homostyles, the higher will be the estimated proportion of crossing. When this viability is 75.63 per cent. the estimated amount of crossing is roo per cent. and the data will not 
tolerate a value lower than this. Allowing for any illegitimate crosses $S^{h} s \times s s$ has a similar effect.

An obvious possible explanation for the deficiency of pins is that they have a lower viability relative to all other forms. On this assumption the years $1946-54$ give an estimate of 66.88 per cent. for the relative viability of the pins, with an estimated standard error of $5 \cdot 15$ per cent. However, in the years $195^{6}$ and 1957 , only progenies from isolated homostyles, forced to self-fertilise, have been grown. The two years show no heterogeneity and give $130 / 520$ for the total proportion of pins from segregating progenies. The contingency $\chi^{2}$ testing the difference between this proportion and that observed for the years $1946-54$ is 10.2 for one degree of freedom, giving a probability less than 0.5 per cent. Since, apart from the isolation of the parent homostyles, these later progenies have been grown in conditions as similar to those of previous years as the experimental controls will allow, this difference can only be attributed to the enforced selffertilisation of the parent homostyles.

\section{A POSSIBLE REASON FOR CROSSING}

In 1957 a further experiment was set up, in order to investigate the reasons previously put forward for the self-fertilisation of the homostyles, viz. the close proximity of stigma and anthers and the early dehiscence of the latter.

A number of plants were chosen at random from ten of the progenies and individual flowers on each plant marked with coloured thread when still in bud. From the time when the flower had first opened sufficiently for the stigma to be easily visible, the difference in height between the stigma and the anthers was recorded each day for about six days, according to the scoring system indicated in fig. I. Scores of o, 1, 2, 3 or 4 were assigned to flowers as the position of the stigma varied from below the anthers to well above them. The state of the anthers, i.e. whether they had dehisced or not, was also recorded each day. This comparatively rough scoring system was adopted in order not to damage the flowers when recording and so disturb the natural progress of their growth.

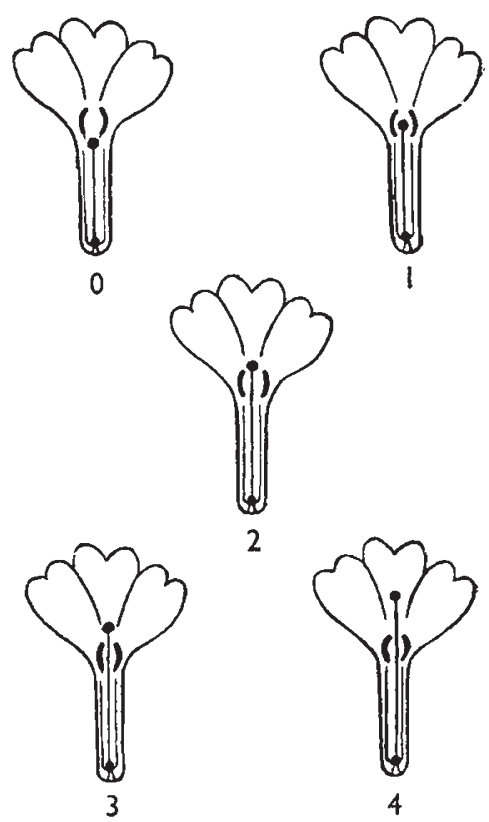

Frg. I-Diagrams of half-flowers of $P$. vulgaris, showing typical examples from each of the scoring categories o to 4 .

It was found that, in general, when the flower was first scored, the stigma was well above or just on top of the anthers, and that as the 
corolla grew, the difference in height decreased until the stigma was below the anthers. In a number of cases the stigma actually protruded

TABLE 2

Distribution of scores for total change in relative height of stigma and anthers

\begin{tabular}{|c|c|c|c|c|c|c|c|c|c|c|c|}
\hline \multirow{2}{*}{ Score } & \multicolumn{10}{|c|}{ Progeny no. } & \multirow{2}{*}{ Total } \\
\hline & 24 & 23 & I I & I 2 & I 3 & I 4 & 17 & 20 & 19 & I 5 & \\
\hline o & 3 & I & 6 & 6 & 0 & I & 3 & 4 & 2 & 2 & 28 \\
\hline I & 8 & 5 & 9 & 10 & 3 & 6 & 12 & 10 & 7 & I I & 81 \\
\hline 2 & 3 & 12 & 6 & II & II & 9 & 8 & 14 & 7 & 14 & 95 \\
\hline 3 & I & 5 & IO & 3 & IO & 7 & 4 & i & 7 & 9 & 57 \\
\hline 4 & 0 & 0 & I & 0 & 0 & 2 & o & o & o & 3 & 6 \\
\hline Total & I 5 & 23 & $3^{2}$ & 30 & 24 & 25 & 27 & 29 & 23 & 39 & 267 \\
\hline
\end{tabular}

Heterogeneity $\chi^{2}=46 \cdot 6282$ for 27 degrees of freedom $\mathrm{P} \approx \mathrm{I}$ per cent.

out of the bud. The overall average number of days from first recording a flower to dehiscence of its anthers was 2.75 , and the flowers were usually fully open before dehiscence had occurred. The

TABLE 3

Distribution of number of days to dehiscence

\begin{tabular}{|c|r|r|r|r|r|r|r|r|r|r|r|}
\hline $\begin{array}{c}\text { No. of } \\
\text { days }\end{array}$ & \multicolumn{10}{|c|}{ Progeny no. } & Total \\
& 24 & 23 & II & 12 & I3 & 14 & 17 & 20 & 19 & 15 & \\
\hline & & & & & & & & & & & \\
0 & 1 & 1 & 1 & 1 & 0 & 0 & 0 & 1 & 0 & 0 & 5 \\
I & 2 & 4 & 6 & 8 & 2 & 2 & 6 & 5 & 4 & 1 & 40 \\
2 & 6 & 5 & 5 & 6 & 9 & 7 & 6 & 9 & 5 & 9 & 67 \\
3 & 5 & 7 & 8 & 8 & 5 & 14 & 9 & 9 & 3 & 8 & 76 \\
4 & 0 & 4 & 10 & 7 & 7 & 2 & 4 & 5 & 6 & 17 & 62 \\
5 & I & 2 & 2 & 0 & 1 & 0 & 2 & 0 & 5 & 4 & 17 \\
Total & I5 & 23 & 32 & 30 & 24 & 25 & 27 & 29 & 23 & 39 & 267 \\
\hline
\end{tabular}

Heterogeneity $\begin{aligned} \chi^{2} & =47 \cdot 484 \mathrm{I} \text { for } 27 \text { degrees of freedom } \\$\[ \]$ & \approx \text { I per cent. }\end{aligned}$

stigmas of forty buds, arbitrarily selected, and whose anthers had not yet dehisced, were all found to be receptive to pollen. Hence we have here a situation well known to favour outcrossing in many species.

The distributions of the scores for the total change in relative height of stigma and anthers (as measured by the difference between the initial and final scores recorded), the final recorded scores, and the number of days from first recording a flower to dehiscence of its anthers, are given in tables 2-4. In the tables, the results from plants within progenies are combined. 
There is clearly considerable variation in all these characters. A contingency $\chi^{2}$ calculated from the tables indicates whether the difference between the progeny distributions is significant, and thus

TABLE 4

Distribution of final score

\begin{tabular}{|c|c|c|c|c|c|c|c|c|c|c|c|}
\hline \multirow{2}{*}{ Score } & \multicolumn{10}{|c|}{ Progeny no. } & \multirow{2}{*}{ Total } \\
\hline & 24 & 23 & I I & I 2 & I 3 & 14 & 17 & 20 & 19 & I 5 & \\
\hline 0 & I3 & 20 & 30 & 25 & I 6 & I 7 & $2 \mathrm{I}$ & 22 & 17 & 37 & 218 \\
\hline I & 2 & 3 & 2 & 5 & 7 & 8 & 5 & 6 & 5 & 2 & 45 \\
\hline$>I$ & o & o & 0 & o & I & o & I & I & I & o & 4 \\
\hline Total & I 5 & 23 & 32 & 30 & 24 & 25 & 27 & 29 & 23 & 39 & 267 \\
\hline
\end{tabular}

Heterogeneity $\chi^{2}=19.5635$ for 9 degrees of freedom

whether there is any evidence for polygenic inheritance of the characters. The $\chi^{2}$ were calculated on grouping the last two rows in tables 2 and 4 and also the first two in table 3. This grouping decreases the sensitivity of the test, and so there can be no doubt of the highly significant heterogeneity indicating polygenic control of the characters.

TABLE 5

Analysis of variance for total growth

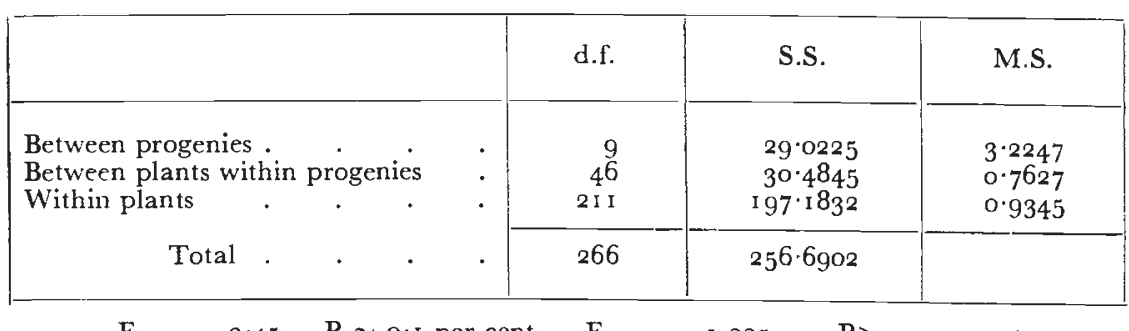

$$
\mathrm{F}_{9,211}=3.45 \quad \mathrm{P} \approx \mathrm{O} \cdot \mathrm{I} \text { per cent. } \quad \mathrm{F}_{211,46}=\mathrm{I} \cdot 225 \quad \mathrm{P}>20 \text { per cent. }
$$

Estimated environmental component of variance $\quad . \quad . \quad . \quad . \quad 0.8026$ Approximately 95 per cent. fiducial limits . . . . . . $0 \cdot 7906-0 \cdot 8{ }_{14} 6$ Estimated component of variance due to differences between progenies . $\quad 0 \cdot 08497$ Approximately 95 per cent. fiducial limits . $. . \quad \cdot 0 \cdot 02668-0 \cdot 3040$

It was not possible to partition the $\chi^{2}$ further in order to investigate the differences between plants within progenies, as the expectations would be too small.

The analyses of variance for total growth and number of days to dehiscence are given in tables 5 and 6 .

The tests of significance and estimates from the analysis of variance are inefficient because of the coarse grouping of the data, the scoring system used being effectively the grouping of a continuous distribution. 
Thus the significance levels obtained from the tables, testing variation between progenies, are considerably different from those obtained from the contingency $\chi^{2}$ and are less reliable. The differences between plants within progenies are not significant. This is to be expected as the progenies are the result of at least two generations selfing, and so the major part of the heritable variation should lie in the differences between the parents.

Since there was no significant difference between the S.S. within plants and the S.S. between plants within progenies, these were amalgamated and estimated components of variance calculated, using Sheppherd's correction (Kempthorne, I950). The approximate fiducial intervals for the between-progenies components were calculated by the method of Bross (r950).

The correlation coefficient between the number of days to dehiscence and the score for total growth, is highly significant at 0.6136 for

TABLE 6

Analysis of variance of number of days to dehiscence

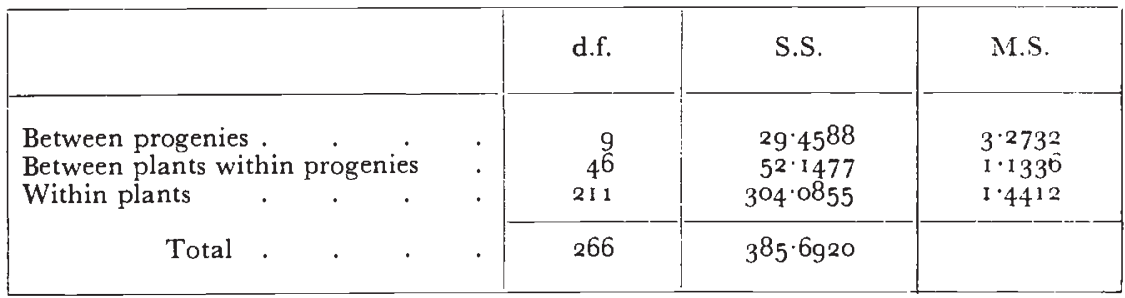

$\mathrm{F}_{9,211}=2.27 \mathrm{I} \quad \mathrm{P} \approx 2.5$ per cent. $\quad \mathrm{F}_{211,46}=1.27 \mathrm{I} \quad \mathrm{P}>20$ per cent.

Estimated environmental component of variance

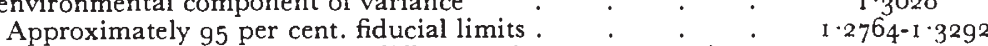

Approximately 95 per cent. fiducial limits .
Estimated component of variance due to differences between progenies .

0.0711

Approximately 95 per cent. fiducial limits .

$0 \cdot 0097-0 \cdot 2820$

266 d.f. This may mean either that there was a tendency to start recording flowers with a high initial score at an earlier stage in their growth, or that the two characters are in some way developmentally connected, or possibly both.

It may be noted that in a quantitative experiment of this kind, where measurements of a character are made on the flowers, the S.S. within plants gives a direct estimate of the environmental component of variance, without any assumptions concerning pure lines.

\section{DISCUSSION}

There are doubtless other factors, such as differential pollen-tube growth, which may affect the cross-fertilisation of the homostyle plants. However, a preliminary investigation did not show up any such differences. Most of the 1957 experiment took place in hot sunny weather, and so the results could not be explained by the sort of weather conditions that are known to favour late dehiscence. 
Hence it seems that in considering the dynamics of the changes in the Primula populations containing homostyle plants, the crossfertilisation of the latter must be taken into account.

The data given in the previous section indicate that, although there is evidence for polygenic control of the amount of cross-fertilisation, there is considerable environmental variation. Thus the amount of cross-fertilisation may be expected to vary from year to year, as is borne out by the results of the breeding experiment for 1955 .

There exist three possibilities with respect to the tendency of the homostyles to cross.

(a) It is the residual of a tendency that existed in conjunction with the complete illegitimacy system.

(b) It is a tendency which has been selected for as the proportion of homostyles in populations increased, because of the advantage of outcrossing.

(c) The tendency existed with the complete illegitimacy system and has been further selected for as the proportion of homostyles increases.

By observing the number of days to dehiscence in pins from populations with a small proportion of homostyles, and studying the variation in the amount of crossing between homostyles from populations with different proportions of homostyles, it is hoped to gain some information about these possibilities. If $(a)$ were true, the pins would also dehisce late and there would be no significant variation in the amount of crossing between homostyles from different populations. On the other hand, if $(b)$ held, the pins would dehisce early, and the amount of crossing could be expected to vary more or less directly with the proportion of homostyles in a population, (c) being the intermediate possibility. If such a tendency to cross does exist with the illegitimacy system, it does not seem improbable that it arose out of selection favouring an increased efficiency of the illegitimacy system, a type of situation suggested by Mather and De Winton (I94I). Whichever possibility is true, it does not appear that the change to homostyly in the populations is an abrupt change from an outbreeding to an inbreeding system (Crosby, I949 and I954).

Certainly the situation in the Primula populations is more complicated than has hitherto been supposed and it is hoped, soon, to publish a more detailed theoretical investigation of the possible explanations for the observed changes.

\section{SUMMARY}

In Primula vulgaris, a significant deficiency of pins was observed amongst the progeny of segregating homostyles, which had pollinated in open-pollination plots. An experiment on the homostyle flowers showed that their anthers dehisced late, and revealed a characteristic 
pattern of relative growth of the stigma and anthers. These observations afford considerable evidence for the occurrence of natural crossing between homostyle plants of Primula vulgaris. This should therefore be taken into account when considering the dynamics of changes in the Primula populations and is probably a factor of some evolutionary significance.

Acknuzwledgments. - I would like to thank Professor Sir Ronald Fisher, F.R.s., for his suggestions and encouragement in the course of this investigation, and Mrs V. C. Fyfe, who first suggested the possibility of crossing and why it might occur and collected much of the data. I would also like to thank Mr H. Mowl for drawing the diagrams, and acknowledge the receipt of an Agricultural Research Council Studentship while doing this work.

\section{REFERENCES}

13ROSS, IRWIN. I950. Fiducial intervals for variance components. Biometrics, 6, I36-I 44 .

CROSBY, J. L. 1949. Selection of an unfavourable gene complex. Evolution, 3, 21 2-230.

CROSBY, J. I. I 954. Populations and evolution : the significance of incompatibility. Proc. of the 8th Inter. Bot. Congress.

ERNST, A. 1928. Zur Vererbung der morphologischen Heterostyliemerkmale. Ber. Deuts. Bot. Ges., 46, 573-588.

kempthorne, o. 1950. Design and Analysis of Experiments. Wiley Statistical Publications.

MATHER, K., AND DE WINTON, D. I94I. Adaptation and counter-adaptation of the breeding system in Primula. Ann. Bot., N.S. 5, 297-3II. 